\title{
On the Safe-Haven Ability of Bitcoin, Gold, and Commodities for International Stock Markets: Evidence from Spillover Index Analysis
}

\author{
Qian Wang $\mathbb{D}^{D}$, Yu Wei $\mathbb{D}^{\mathbb{C}}$, Yao Wang $\mathbb{D}$, and Yuntong Liu \\ School of Finance, Yunnan University of Finance and Economics, Kunming, Yunnan 650221, China \\ Correspondence should be addressed to Yu Wei; weiyusy@126.com
}

Received 15 November 2021; Accepted 18 December 2021; Published 4 January 2022

Academic Editor: Dehua Shen

Copyright (c) 2022 Qian Wang et al. This is an open access article distributed under the Creative Commons Attribution License, which permits unrestricted use, distribution, and reproduction in any medium, provided the original work is properly cited.

\begin{abstract}
Stock market is susceptible to various external shocks for its tight dependence on economic fundamentals, financial speculation, and fragile emotions in massive traders, making it a very risky market for investors. In this paper, we aim to identify whether commonly recognized safe-haven assets, that is, bitcoin, gold, and commodities, can provide investors with effective hedging utility in international stock markets, especially during periods of extreme market turbulence. By using the spillover index method based on the TVP-VAR model, we find that firstly, bitcoin, gold, and commodities can only offer weak hedging effects on stock markets. Furthermore, their abilities to act as a safe haven are ranked as: commodities > gold > bitcoin. Secondly, in general, we have observed the increasing hedging ability of these safe-haven assets in times of extreme market turmoil. Thirdly, among international stock and safe-haven asset markets, the world and the developed stock markets act as the net spillover transmitters, while bitcoin, gold, and commodities are the net recipients. Lastly, the total spillover effects are time-varying and increase significantly after the outbreak of extreme events.
\end{abstract}

\section{Introduction}

"Black swan" events not only can impact the healthy development of the global economy but also can seriously pose a threat to the investors in the financial market. For instance, the outbreak of the European debt crisis deeply affects global stock markets $[1,2]$. Moreover, the COVID-19 pandemic has made the global stock markets fluctuate frequently and led to a cross-market spillover of financial risks [3]. Specifically, the market spillover effects mean that when a "Black swan" event happens in a specific market, the risk would be spread to other markets or the transfer of information from one market to others could be witnessed. In fact, it is extremely difficult to ignore the existence of the market spillovers for investors in view of the returns on the investment portfolio, international investors, and portfolio managers, as the investors are always searching for proper assets or risk diversification. Therefore, it is significant to identify the safe-haven assets on global stock markets when the "Black swan" events occur.
Generally, gold, bitcoin, as well as commodities are considered three popular safe havens for stocks [4-6]. However, the conclusions on the hedging abilities of these assets have not reached a consensus on account of the timevarying properties of risk spillover, which makes it difficult for investors to compare the performances of gold, bitcoin, and commodities as a safe haven of the stock markets when extreme events occur [7].

Scholars have long debated on the performance of gold as a hedging instrument or a safe haven for stocks. Conventionally, as the saying of "gone with the gold," gold is regarded as an effective instrument protecting stock market investment from a decline [8-11]. For example, Triki and Ben Maatoug [12] analyzed the relationship between gold prices returns and the S\&P500 stock index during the 1985 to 2018 period using the DCC MV-GARCH model to test the hedging role of gold and found that gold is a good diversifier and safe haven, particularly during the great tension. Additionally, He et al. [13] stated that gold does act as a good 
diversifier in the US and the UK stock indices by applying the basic capital asset pricing model (CAPM). Conversely, recent studies have questioned the conclusions on gold as an effective hedging asset for stock markets [14, 15]. For instance, Disli et al. [16] examined the spillover effects between global equities and gold during the COVID-19 pandemic using a wavelet coherence model and proved gold lose hedging properties because of the nature of the underlying forces of the current pandemic.

The role of bitcoin as a safe-haven asset is also under discussion for years. Some analyses $[17,18]$ have posited that bitcoin can serve as an effective diversifier. For example, Kliber et al. [19] claimed that bitcoin is a safe-haven asset in Venezuela by applying the stochastic volatility model. Bouri et al. [20] used a dynamic conditional correlation model to explore whether bitcoin acts as a hedge and safe haven for major world stock indices (such as MSCI World, MSCI Europe, etc.); the results also verified the hedge and safehaven properties of bitcoin. However, evidences rejecting the saying that bitcoin acts as a safe haven are not rare $[21,22]$. In reaction to the COVID-19 bear market, Choi and Shin [23] utilized a vector autoregression (VAR) model to provide systematic evidence on the relationship among inflation, uncertainty, and bitcoin and gold prices during the COVID-19 pandemic and found that bitcoin prices increased significantly in response to a positive shock on the stock market, suggesting that bitcoin does not serve as a hedge for investment in stock markets.

Commodity indices investments are also debated assets for their safe-haven property. Some scholars believed that commodity indices are safe-haven assets to diversify risk in the stock market [24]. Bekiros et al. [25] proved that commodity indices in general reduced the risk in stock and increased the risk-adjusted performance from the full sample period (2002-2015). By contrast, other studies have asserted that commodities fail to provide a hedge. For example, Ali et al. [26] clarified the roles of commodities as a hedge for international stock markets using the crossquantilogram approach from 2001 to 2018 . Their conclusions proved that commodities were the safe-haven asset for the stock markets in emerging and frontier market groups.

Even though there are already some researches comparing the safe-haven abilities of bitcoin, gold, and commodity by couples. For example, the conditional diversification benefits offered by gold to equity investments in the G7 markets are comparatively much higher and more stable than those of bitcoin [27]. However, there is still a lack of empirical comparison among the safe-haven properties of bitcoin, gold, and commodities against world, developed, and emerging stock markets.

Several inadequacies exist in the research on the spillover among safe-haven instruments for stock markets during the market downturn. In the literature on which is proper safehaven assets for stock markets, the relative importance of bitcoin, gold, and commodities seems not to be specific. Furthermore, the current study, which is to compare the role of bitcoin, gold, and commodities as a safe haven for stock markets during extreme events from a dynamic standpoint, has been ignored. Moreover, directional net spillover has long been ignored by most studies. For example, Shahzad et al. [6] analyzed the safe-haven property by the crossquantilogram model. Bouri et al. [4] utilized a wavelet coherency approach to compare the safe-haven roles, which clearly ignored net directional spillover of safe-haven assets.

In order to identify the most effective safe-haven assets for stock markets in different periods, we use the TVP-VAR (time-varying parameter vector autoregressive) model by estimating the spillovers among bitcoin, gold, and commodities and stock markets following Diebold and Yilmaz [28]. The benefits of these methods are as follows. (1) Compared with the VAR (vector autoregressive) model, by using the TVP-VAR model, we can easily capture the potential time-varying features in the economy in a flexible and robust way. (2) The parameters in the model are assumed as a stochastic wandering process, which portray the spillover effects for multiple markets at different time points in a better way. (3) The window size is not necessary to be selected, which has the advantage of containing all the information without losing observations. (4) In the view of the net directional spillover analysis, the model applied is particularly useful in distinguishing the net transmitters and net receivers of a system. (5) The model can be more effective for identifying the attribute of a safe haven, as the rolling window analyses reveal evidence of time-variation in the safe-haven roles [6].

Therefore, this paper addresses the question of whether bitcoin, gold, and commodities exhibit a safe-haven property for the stock markets when facing the "black swan" events by adopting dynamic spillover method. This study makes contributions to the existing literature in three aspects: on one hand, this paper compares the performances of bitcoin, gold, and commodities as safe havens for world, developed, and emerging stock markets during the European debt crisis and COVID-19 pandemic from the perspectives of dynamic spillover to propose references for investors in searching for the best asset as hedge objectives during black swan events in the stock market. On the other hand, to the best of our knowledge, most studies on safe haven have only focused on the full sample phase, while we divide our sample into three phases according to the European debt crisis and COVID-19 pandemic to help investors alter their investment strategies during different periods. What is more, our research employs TVP-VAR based on the study of Diebold and Yilmaz [28], which is useful in recognizing the main transmitter and recipient, and provides information to the investors in forming strategies across markets.

The remaining part of the paper proceeds as follows. Section 2 is concerned with the methodology used for this study. Section 3 gives a brief overview of the data. The findings of the study are focused on Section 4. Section 5 displays the robustness of the empirical results by using a static spillover measurement and a dynamic framework on three different rolling windows. The conclusions are presented in Section 6. 


\section{Methodology}

2.1. Time-Varying Parameter Vector Autoregressive Model. There are a number of instruments available for measuring the spillover among variables. The Bayesian time-varying parameter vector autoregressive (TVP-VAR) method is one of the practical ways of capturing the dynamic spillover between a variety of financial products.

Firstly, a structural vector autoregressive (SVAR) model is constructed as follows:

$$
A y_{t}=F_{1} y_{t-1} n+\cdots+F_{s} y_{t-s}+\mu_{t}, \quad t=s+1, \ldots, n,
$$

where $y_{t}$ is the $k \times 1$ dimensional observed variable; in this paper, $y_{t}$ is the observed variable of $6 \times 1$ dimensional consisting of bitcoin, gold, commodities index, world, developed, and emerging stocks. $A, F_{1}, \ldots, F_{s}$ are $k \times k$ dimensional coefficient matrices. The residuals $\mu_{t}$ is $k \times 1$ dimensional structural shock variables, and the contemporaneous relationship of the structural shocks is defined as a lower triangular matrix $A: A=\left(\begin{array}{cccc}1 & 0 & \ldots & 0 \\ a_{21} & \ddots & \ddots & \vdots \\ \vdots & \ddots & \ddots & 0 \\ a_{k 1} & \ldots & a_{k, k-1} & 1\end{array}\right)$.

On the basis of the above model, we rewrite equation (1) as a VAR model in reduced form as follows:

$$
y_{t}=B_{1} y_{t-1}+\cdots+B_{s} y_{t-s}+A^{-1} \sum \varepsilon_{t}
$$

where $\quad \varepsilon_{t} \sim N\left(0, I_{k}\right), \quad B_{i}=A^{-1} F_{i}, \quad i=1, \ldots, s$, $\Sigma=\left(\begin{array}{cccc}\sigma_{1} & 0 & \ldots & 0 \\ 0 & \ddots & \ddots & \vdots \\ \vdots & \ddots & \ddots & 0 \\ 0 & \ldots & 0 & \sigma_{k}\end{array}\right)$, and $\sigma_{i}(i=1, \ldots, k)$ is the standard deviation of the structural shock. The elements in $B$ is stacked by means of a row stack into a $k^{2} s \times 1$ dimensional column vector $\beta$, defined by $X_{t}=I_{k} \otimes\left(y_{t-1}, \ldots, y_{t-s}\right)$, where $\otimes$ denotes the Kronecker product. Then equation (2) can be expressed as follows:

$$
y_{t}=X_{t} \beta+A^{-1} \sum \varepsilon_{t} .
$$

Then, a time-varying vector autoregression model is defined as follows:

$$
y_{t}=X_{t} \beta_{t}+A_{t}^{-1} \sum_{t} \varepsilon_{t}
$$

where coefficient $\beta_{t}$, parameters $A_{t}$, and covariance matrix of random fluctuations $\sum_{t}$ are both time-varying in nature. Let $a_{t}$ is a stacked element in the lower triangular matrix $A_{t}$, then denoted $a_{t}$ as $a_{t}=\left(a_{21}, a_{31}, a_{32}, a_{41}, \ldots, a_{k, k-1}\right)$. At the same time, we suppose $h_{t}=\left(h_{1 t}, \ldots, h_{k t}\right)^{\prime}$, where $h_{j t}=\log \sigma_{j t}^{2}$, $j=1, \ldots, k, t=s+1, \ldots, n$.

Del Negro and Primiceri [29] proposed that even if the parameters are smooth and stable, the constructed model still has many parameters to be estimated. In this paper, we assume that all parameters in equation (4) obey the firstorder random wandering process to reduce the number of parameters to be estimated, which finally results in: $\beta_{t+1}=\beta_{t}+\mu_{\beta t}, a_{t+1}=a_{t}+\mu_{a t}$, and $h_{t+1}=h_{t}+\mu_{h t}$; in the meantime,

$$
\left(\begin{array}{c}
\varepsilon_{t} \\
\mu_{\beta t} \\
\mu_{a t} \\
\mu_{h t}
\end{array}\right) \sim N\left(0,\left(\begin{array}{cccc}
I & 0 & 0 & 0 \\
0 & \sum_{\beta} & 0 & 0 \\
& \beta & & \\
0 & 0 & \sum_{a} & 0 \\
0 & 0 & 0 & \sum_{h}
\end{array}\right)\right),
$$

where $\quad t=s+1, \ldots, n, \quad \beta_{s+1} \sim N\left(\mu_{\beta_{0}}, \sum_{\beta_{0}}\right), \quad a_{s+1} \sim N$ $\left(\mu_{a_{0}}, \Sigma_{a_{0}}\right)$, and $h_{s+1} \sim N\left(\mu_{h_{0}}, \Sigma_{h_{0}}\right)$. Assuming $\sum_{\beta}, \sum_{a}$, and $\sum_{h}$ are symmetry matrices, which accounts for time-varying parameters $\beta_{t}, a_{t}$, and $h_{t}$ mutually irrelevant.

2.2. Spillover Indices Based on Diebold-Yilmaz Methods. In order to calculate the generalized impulse response functions (GIRF) and generalized forecast error variance decomposition (GFEVD), VAR can be transformed into an infinite-order vector moving average (VMA) process [30]:

$$
y_{t}=\sum_{k=0}^{\infty} L^{\prime} W_{t}^{k} L \varepsilon_{t-k}, y_{t}=\sum_{k=0}^{\infty} A_{k t} \varepsilon_{t-k},
$$

where $L=\left[I_{N}, \ldots, O_{p}\right]^{\prime}, W=\left[\beta_{t} ; I_{N(p-1)}, O_{N(p-1) \times N}\right]$, and $A_{j t}$ represent, respectively, an $N p \times N, N p \times N p$, and $N \times$ $N$ dimensional matrix.

The $\mathrm{GIRF}_{s}$ reveals that to what extent the trajectory of a variable is due to the impact of itself or other variables in the system. The variance decomposition method measures the proportion of prediction error variance in any endogenous variable affected by different information shocks in the VAR system [31, 32]. The proportion explained by the variable $k$ in the $H$-step-ahead prediction error variance of variable $j$, which can be calculated by

$$
\begin{aligned}
\operatorname{GIRF}_{t}\left(H, \delta_{k, t}, F_{t-1}\right) & =E\left(Y_{t+H} \mid \varepsilon_{k, t}=\delta_{k, t}, F_{t-1}\right)-E\left(Y_{t+H} \mid F_{t-1}\right), \\
\Psi_{k, t}^{g}(H) & =\frac{A_{H, t} S_{t} \varepsilon_{k, t}}{\sqrt{S_{k k, t}}}-\frac{\delta_{k, t}}{\sqrt{S_{k k, t}}} \\
\Psi_{k, t}^{g}(H) & =\frac{1}{\sqrt{S_{k k, t}}} A_{H, t} S_{t} \varepsilon_{k, t},
\end{aligned}
$$

where $\Psi_{k, t}^{g}(H)$ represents the $\mathrm{GIRF}_{s}$ of variable $k, \delta_{k, t}$ represents selection vector with one on the $k$-th position and zero otherwise, and $F_{t-1}$ the information set until $t-1$. In the next moment, GFEVD is $\widetilde{\phi}_{k j, t}^{g}(H)$, which can be explained the variance share one variance has on others.

$$
\widetilde{\phi}_{j k, t}^{g}(H)=\frac{\sum_{t=1}^{H-1} \Psi_{j k, t}^{2, g}}{\sum_{k=1}^{N} \sum_{t=1}^{H-1} \Psi_{j k, t}^{2, g}},
$$

where $\sum_{k=1}^{N} \tilde{\phi}_{j k, t}^{g}(H)=1$ and $\sum_{j, k=1}^{N} \tilde{\phi}_{j k, t}^{g}(H)=N$. According to the GFEVD, the total spillover index measures the overall 
spillover level of bitcoin, gold, commodities, and stock markets systems, which reveals the influence proportion of information spillover contribution to system change.

$$
\begin{aligned}
C_{t}^{g}(H) & =100 * \frac{\sum_{j, k=1, j \neq k}^{N} \widetilde{\phi}_{j k, t}^{g}(H)}{\sum_{j, k=1}^{N} \widetilde{\phi}_{j k, t}^{g}(H)} \\
& =100 * \frac{\sum_{j, k=1, j \neq k}^{N} \widetilde{\phi}_{j k, t}^{g}(H)}{N} .
\end{aligned}
$$

First of all, we can measure the directional spillover variable $j$ transmits its shock to all other variables $k$, called total directional spillover to others and defined as follows:

$$
C_{j \longrightarrow k, t}^{g}(H)=100 * \frac{\sum_{k=1, j \neq k}^{N} \widetilde{\phi}_{k j, t}^{g}(H)}{\sum_{k=1}^{N} \widetilde{\phi}_{k j, t}^{g}(H)} .
$$

Then, the total directional spillover from others that variable $j$ receives it from variables $k$ in a similar pattern and defined as follows:

$$
C_{j \leftarrow k, t}^{g}(H)=100 * \frac{\sum_{k=1, j \neq k}^{N} \widetilde{\phi}_{j k, t}^{g}(H)}{\sum_{j=1}^{N} \widetilde{\phi}_{j k, t}^{g}(H)} .
$$

At last, we figured the net directional spillover as follows:

$$
C_{j, t}^{g}=C_{j \longrightarrow k, t}^{g}(H)-C_{j \leftarrow k, t}^{g}(H),
$$

where $C_{j, t}^{g}$ helps identify the nature of the market that whether it is a net receiver or a net transmitter. Furthermore, the sign of the net total directional spillover illustrates if variable $j$ is driving the network $\left(C_{j, t}^{g}>0\right)$ or driven by the network $\left(C_{j, t}^{g}<0\right)$. In other words, in the case where variable $j$ is driven by the network $\left(C_{j, t}^{g}<0\right)$, variable $j$ is viewed as a safe-haven asset.

\section{Data}

In this paper, our data set covered three potential safe-haven assets, namely, bitcoin, gold, commodities, and the stock market indices of world, developed, and emerging markets. A newly emerged digital asset, bitcoin's daily closing prices (00:00) are recorded from the website https:// coinmarketcap.com/. For gold, the price used in this study is the Gold Fixing Price 10:30 a.m. (London time) in London Bullion Market, based in US dollars. The commodity index is the S\&P Goldman Sachs Commodity Index (S\&P GSCI) that represents the most widely used benchmark index in the commodity market [4]. For stock markets, the three stock indices (world, developed, and emerging markets) are represented by the corresponding Morgan Sanely Capital International (MSCI) indices.

We define the daily returns as the difference between the natural logarithm of two consecutive closing prices as $r_{t}=\ln \left(P_{t}\right)-\ln \left(P_{t-1}\right) \cdot \operatorname{Ln}\left(P_{t}\right)$ denotes the natural logarithm of the closing price at the time. The data spans from July 20, 2010, to June 23, 2021. The starting point of the sample phase is constrained by the availability of bitcoin data. Data with inconsistent trading time due to holidays or other factors are excluded; thereby, we have a total of 2,704 observations for each variable. The sample is further divided into three phases: phase I is ended by the phase of the European debt crisis, from July 20, 2010, to March 13, 2012, when the Greek parliament has approved the country's agreement with the European Union and the International Monetary Fund on a second bailout package, and the award of 130 billion euros (\$171 billion) in new loans to Greece has gone a long way toward curbing the European debt crisis; phase II is economic calm, from March 14, 2012, to January 13, 2020, when the first cross-border COVID-19 transmission of infection was reported by the World Health Organization; and phase III is started with the outbreak of the COVID-19 pandemic, from January 14, 2020, to June 23, 2021.

In Table 1, we present the descriptive statistics of all the return series in our sample. It can be seen that all the means of returns are positive, except for commodities that have a negative mean return. Bitcoin is the riskiest asset, whereas emerging markets are the least risky asset. Broadly, the fattail is more prominent during phases I and III than phase II. Moreover, all of them are leptokurtic and not normally distributed according to the excess kurtosis and Jarque-Bera tests. Then they also have a high-degree of autocorrelations by the Ljung-Box Q statistics. The autocorrelation for gold is significantly stronger during phase III. Lastly, we check for the presence of unit roots using the augmented Dickey-Fuller (ADF) and Phillips-Perron (P-P) test statistics. The ADF and P-P show that all the return series are stable and satisfy the modeling conditions.

\section{Empirical Results}

4.1. Total Spillover. As can be seen from Figure 1, the dynamic total spillover effects (defined in equation (12)) among bitcoin, gold, commodities, and world, developed, emerging stock markets show significant time-varying characteristics, ranging from almost $20 \%$ to $80 \%$, demonstrating a relatively strong information spillover among the bitcoin, gold, commodities, and three stock markets. That is, the risk of one market is likely to be transferred to other markets. More specifically, the dynamic total average spillover is $39.37 \%$ during phase II, while it is $50.84 \%$ and $48.43 \%$ in phases I and III, respectively. The six markets' dynamic total average spillover effects increase significantly during the European debt crisis and COVID-19 health pandemic, which means the contagion of risk is more sensitive when crisis events occur. Moreover, the most significant spike within the sample interval is observed at the beginning of 2020 when the COVID-19 occurred. With the government's control of the epidemic situation and people's understanding and attention to the epidemic situation, a downward trend is witnessed in spillover, decreasing from $75 \%$ to $40 \%$.

To sum up, the above findings imply that the major "swan" events may enhance the information or risk spillover transmissions among bitcoin, gold, commodities, and three stock markets and increase the total spillover effects among the probable safe-haven assets and stock markets. With further deepening economic globalization, the rapid improvement of medical standards, and the continuous 
TABLE 1: Descriptive statistics of all return series.

\begin{tabular}{|c|c|c|c|c|c|c|}
\hline & Bitcoin & Gold & Commodities & World & Developed & Emerging \\
\hline \multicolumn{7}{|c|}{ Entire phase: July 20, 2010-June 23, 2021} \\
\hline Observations & 2704 & 2704 & 2704 & 2704 & 2704 & 2704 \\
\hline Mean & 0.0047 & 0.0001 & -0.0002 & 0.0003 & 0.0003 & 0.0001 \\
\hline Standard deviation & 0.0768 & 0.0099 & 0.0132 & 0.0093 & 0.0096 & 0.0102 \\
\hline Minimum & -0.8488 & -0.0970 & -0.1252 & -0.0999 & -0.1044 & -0.0694 \\
\hline Maximum & 1.4742 & 0.0493 & 0.0762 & 0.0806 & 0.0841 & 0.0557 \\
\hline Skewness & 2.5801 & -0.6755 & -0.7964 & -1.1364 & -1.1081 & -0.5618 \\
\hline Excess kurtosis & 68.7331 & 9.6108 & 11.9570 & 19.2062 & 19.9086 & 7.6602 \\
\hline Jarque-Bera & $489814.3^{* * *}$ & $5129.4^{* * *}$ & $9324.8^{* * *}$ & $30172.9^{* * *}$ & $32764.9^{* * *}$ & $2589.1^{* * *}$ \\
\hline$Q(5)$ & $22.3930^{* * *}$ & 3.5407 & $16.5090^{* * *}$ & $40.1330^{* * *}$ & $37.9040^{* * *}$ & $84.6500^{* * *}$ \\
\hline$Q(10)$ & $29.5070^{* * *}$ & 5.0090 & $20.7670^{* *}$ & $115.4700^{* * *}$ & $128.2500^{* * *}$ & $93.6780^{* * *}$ \\
\hline$Q(20)$ & $45.7420^{* * *}$ & 14.8400 & $33.8330^{* *}$ & $152.7000^{* * *}$ & $172.0400^{* * *}$ & $101.1500^{* * *}$ \\
\hline $\mathrm{ADF}$ & $-53.6237^{* * *}$ & $-51.2561^{* * *}$ & $-53.9454^{* * *}$ & $-16.9024^{* * *}$ & $-16.9627^{* * *}$ & $-31.9317^{* * *}$ \\
\hline $\mathrm{P}-\mathrm{P}$ & $-53.6050^{* * *}$ & $-51.2512^{* * *}$ & $-54.0550^{* * *}$ & $-50.0002^{* * *}$ & $-51.9171^{* * *}$ & $-44.5217^{* * *}$ \\
\hline \multicolumn{7}{|c|}{ Phase I: July 20, 2010-March 13, 2012} \\
\hline Observations & 379 & 379 & 379 & 379 & 379 & 379 \\
\hline Mean $(\%)$ & 0.0105 & 0.000916 & 0.0007 & 0.000462 & 0.000484 & 0.000319 \\
\hline Standard deviation & 0.1263 & 0.012317 & 0.013933 & 0.011993 & 0.01234 & 0.012693 \\
\hline Minimum & -0.4308 & -0.05679 & -0.06744 & -0.05223 & -0.05256 & -0.06524 \\
\hline Maximum & 0.6931 & 0.037309 & 0.04661 & 0.043098 & 0.046433 & 0.048096 \\
\hline Skewness & 0.7216 & -0.56693 & -0.61513 & -0.42635 & -0.37636 & -0.56629 \\
\hline Excess kurtosis & 8.9885 & 5.463482 & 5.345873 & 5.57309 & 5.553498 & 5.407944 \\
\hline Jarque-Bera & $599.2170^{* * *}$ & $116.1377^{* * *}$ & $110.8051^{* * *}$ & $116.0354^{* * *}$ & $111.9143^{* * *}$ & $111.8194^{* * *}$ \\
\hline$Q(5)$ & 3.2423 & 0.6646 & 3.0721 & $13.8870^{* *}$ & $13.115^{* *}$ & $25.029^{* * *}$ \\
\hline$Q(10)$ & 8.3026 & 10.1590 & 13.5230 & $18.3170^{* *}$ & $17.448^{* * *}$ & $27.240^{* * *}$ \\
\hline$Q(20)$ & 21.4110 & 17.8200 & 19.1980 & 27.9300 & $27.198^{* *}$ & $33.366^{* *}$ \\
\hline $\mathrm{ADF}$ & $-20.5191^{* * *}$ & $-18.9369^{* * *}$ & $-19.9059^{* * *}$ & $-17.7343^{* * *}$ & $-18.5337^{* * *}$ & $-15.32656^{* * *}$ \\
\hline $\mathrm{P}-\mathrm{P}$ & $-20.4961^{* * *}$ & $-18.9299^{* * *}$ & $-19.9029^{* * *}$ & $-17.6561^{* * *}$ & $-18.5378^{* * *}$ & $-15.25227^{* * *}$ \\
\hline \multicolumn{7}{|c|}{ Phase II: March 3, 2012-January 13, 2020} \\
\hline Observations & 1961 & 1961 & 1961 & 1961 & 1961 & 1961 \\
\hline Mean $(\%)$ & 0.00374 & $-3.87 E-05$ & -0.00038 & 0.000276 & 0.000307 & $3.58 E-05$ \\
\hline Standard deviation & 0.067284 & 0.009058 & 0.011619 & 0.006921 & 0.007041 & 0.008796 \\
\hline Minimum & -0.84883 & -0.09704 & -0.06586 & -0.04881 & -0.05029 & -0.05128 \\
\hline Maximum & 1.47418 & 0.045897 & 0.076166 & 0.029864 & 0.029383 & 0.043654 \\
\hline Skewness & 4.461687 & -0.69559 & 0.006042 & -0.61131 & -0.62609 & -0.21999 \\
\hline Excess kurtosis & 137.811 & 12.17903 & 6.054368 & 6.624474 & 6.669165 & 5.055585 \\
\hline Jarque-Bera & $1491474^{* * *}$ & $7042.443^{* * *}$ & $762.2823^{* * *}$ & $1195.523^{* * *}$ & $1228.135^{* * *}$ & $361.0696^{* * *}$ \\
\hline$Q(5)$ & $50.598^{* * *}$ & 1.8772 & $21.817^{* * *}$ & $79.176^{* * *}$ & $59.232^{* * *}$ & $88.070^{* * *}$ \\
\hline$Q(10)$ & $65.767^{* * *}$ & 8.9200 & $26.118^{* * *}$ & $85.493^{* * *}$ & $64.145^{* * *}$ & $99.324^{* * *}$ \\
\hline$Q(20)$ & $74.945^{* * *}$ & 22.666 & $32.858^{* *}$ & $101.82^{* * *}$ & $82.003^{* * *}$ & $107.44^{* * *}$ \\
\hline $\mathrm{ADF}$ & $-22.07981^{* * *}$ & $-44.52072^{* * *}$ & -47.35964 & $-36.87325^{* * *}$ & $-38.06258^{* * *}$ & $-36.33821^{* * *}$ \\
\hline $\mathrm{P}-\mathrm{P}$ & $-44.39223^{* * *}$ & $-44.52230^{* * *}$ & -47.25237 & $-36.39581^{* * *}$ & $-37.67187^{* * *}$ & $-36.32432^{* * *}$ \\
\hline \multicolumn{7}{|c|}{ Phase III: January 14, 2020-June 23, 2021} \\
\hline Observations & 364 & 364 & 364 & 364 & 364 & 364 \\
\hline Mean $(\%)$ & 0.003911 & 0.000388 & $3.04 E-05$ & 0.000607 & 0.000625 & 0.000476 \\
\hline Standard deviation & 0.05345 & 0.011364 & 0.019062 & 0.01521 & 0.015976 & 0.013915 \\
\hline Minimum & -0.49728 & -0.052272 & -0.12522 & -0.09997 & -0.10441 & -0.06943 \\
\hline Maximum & 0.19182 & 0.04934 & 0.071175 & 0.080587 & 0.084062 & 0.055737 \\
\hline Skewness & -2.27269 & -0.817685 & -1.76762 & -1.4396 & -1.3505 & -0.9786 \\
\hline Excess kurtosis & 24.37342 & 7.096871 & 14.46007 & 16.09758 & 15.77715 & 8.544046 \\
\hline Jarque-Bera & $7241.834^{* * *}$ & $295.125^{* * *}$ & $2181.44^{* * *}$ & $2727.518^{* * *}$ & $2586.688^{* * *}$ & $524.2676^{* * *}$ \\
\hline$Q(5)$ & $14.529^{* *}$ & 8.8985 & 4.8698 & $42.706^{* * *}$ & $46.605^{* * *}$ & $15.504^{* * *}$ \\
\hline$Q(10)$ & $22.172^{* *}$ & $16.578^{* * *}$ & 9.4020 & $125.96^{* * *}$ & $141.43^{* * *}$ & $25.195^{* * *}$ \\
\hline$Q(20)$ & $37.942^{* * *}$ & $28.859^{* * *}$ & 20.095 & $157.10^{* * *}$ & $177.07^{* * *}$ & $31.924^{* *}$ \\
\hline $\mathrm{ADF}$ & $-21.98285^{* * *}$ & $-17.94773^{* * *}$ & $-18.70611^{* * *}$ & $-6.224532^{* * *}$ & $-5.147020^{* * *}$ & $-11.19319^{* * *}$ \\
\hline $\mathrm{P}-\mathrm{P}$ & $-21.80890^{* * *}$ & $-17.97224^{* * *}$ & $-18.89272^{* * *}$ & $-21.87236^{* * *}$ & $-22.44193^{* * *}$ & $-19.26622^{* * *}$ \\
\hline
\end{tabular}

Note. The Jarque-Bera statistic tests for the null hypothesis of normality in sample return distribution. $Q(n)$ is the Ljung-Box statistics of the return series for up to $n$-th order serial correlation. ADF and P-P are statistics of augmented Dickey-Fuller and Phillips-Perron unit root tests, respectively, based on the least AIC criterion. The symbols ${ }^{* * *},{ }^{* *}$, and ${ }^{*}$ indicate rejection at the $1 \%, 5 \%$, and $10 \%$ significance level. The whole sample phase spans from July 20 , 2010, to June 23, 2021. 


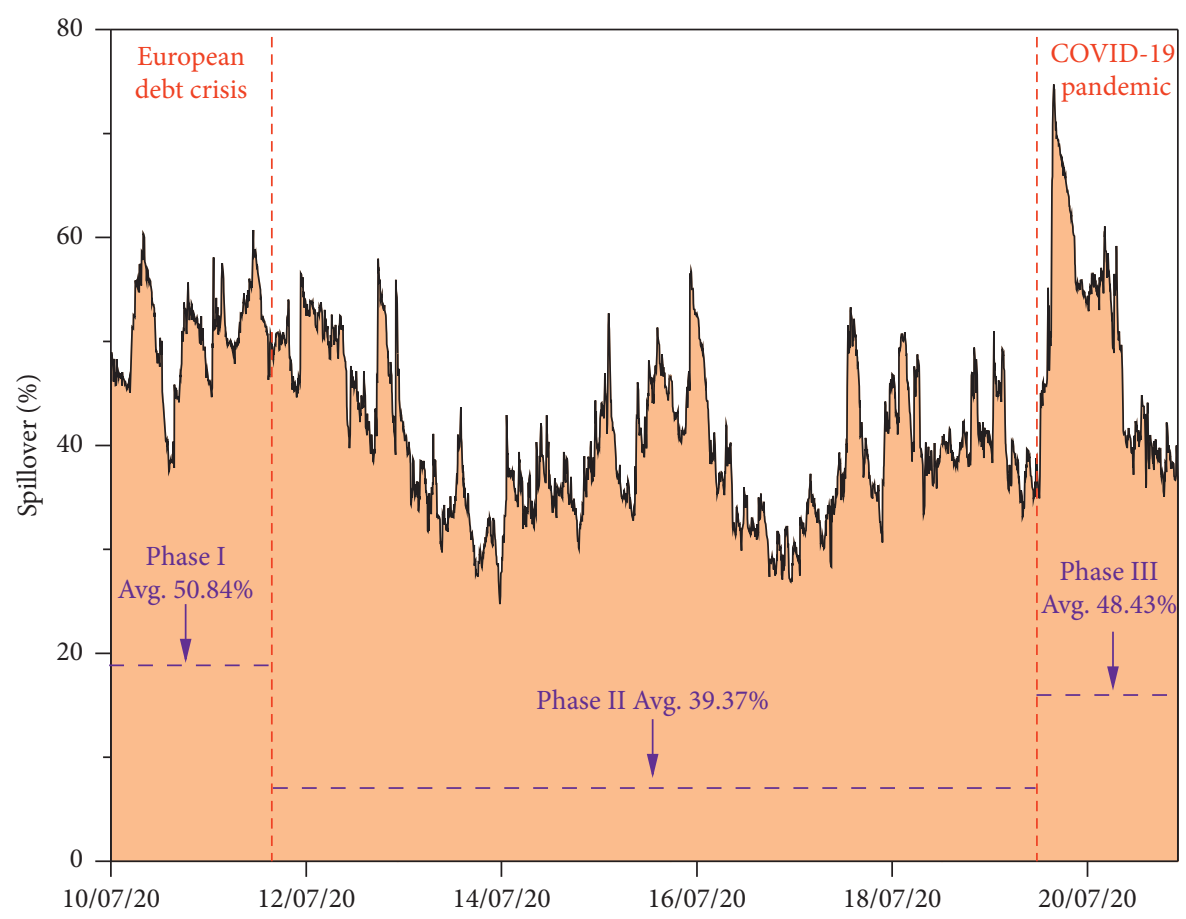

Figure 1: Dynamic return total spillover for TVP-VAR. The orange areas of accumulation define the dynamic return total spillover. The return total spillover plotted here is computed by equation (9). All abbreviations are as follows: bitcoin, gold, and commodities indices (commodities); the world stock index (world); the developed stock index (developed); and the emerging stock index (emerging). The sample period for returns is from July 20, 2020, to June 23, 2021.

innovation of information technology, information or risk spillovers between all kinds of markets in the world are getting stronger. Once an extreme risk event occurs in one market, the negative impacts will quickly transmit to other markets through many channels, such as trade, investment, and speculation, thus further enhancing the spillovers among the probable safe-havens assets and stock markets.

4.2. Net Directional Spillover. The time-varying characteristics of net total directional return spillover from each market to all other markets are shown in Figure 2.

We can find that world and developed stock markets act as the net spillover transmitters, while bitcoin, gold, commodities, and emerging stock market are the net recipients. Further analysis shows that the following:

First of all, as for stock markets, we find that the world stock index makes the largest net spillover transmitter with values of $2.26 \%, 2.56 \%$, and $3.15 \%(1.70 \%, 1.72 \%$, and $2.40 \%$ for the developed stock market), respectively, during the three periods, which demonstrates that the world stock market still occupies the leading status in the whole stock markets. In addition, the emerging stock market is the small net spillover in the stock markets with values of $-0.24 \%$, $-1.49 \%$, and $-1.31 \%$ in phases I, II, and III, respectively. This result is expected considering the slow development and low openness in the stock markets; the emerging stock market has little advantage in the global stock markets; and its fluctuations will have a slender impact on other markets and the global economy.
Interestingly, with regard to the three conceivable safehaven assets, it is obvious that the net total directional spillover effects of bitcoin, gold, and commodities are almost always negative during all sample phases. Furthermore, the negative net total directional spillover means not only the role of the market as a recipient in information spillover but also the role as a hedge asset hedges risk from the investor's perspective. The results are likely to be related to the transfer of information or risk. Therefore, it is fair to claim that these three assets can be considered safe havens for the stock markets. In addition, in phase II, the total net spillover effects of bitcoin, gold, and commodities are $-0.55 \%,-0.99 \%$, and $-1.25 \%$, respectively, and similar results are obtained in phase III $(-0.99,-1.55 \%$, and $-1.70 \%$, respectively). Bitcoin gets the smallest net spillover with a value of $-0.81 \%$ in phase I. However, there is a difference in phases II and III: the net spillover of gold is $-2.06 \%$ much higher than the commodities $(-0.84 \%)$. It seems possible that the above results are due to the event that Spain's stock market plunged 6\% as the debt crisis rattled markets on February 5, 2010, and was warned by Moody's Investors Service on February 26 that if the country does not meet targets in its deficit-reduction plan, Greece's sovereign debt rating would be downgraded within months. It was a time of heightened risk aversion and a sharp sell-off in the euro as investors rushed to get out of a weaker currency. Capital turned to gold as a safe-haven asset, making gold's monetary properties emerge, and prices began to recover.

Last but not least, the commodities index is tightly connected to the stock markets during the negative extreme 


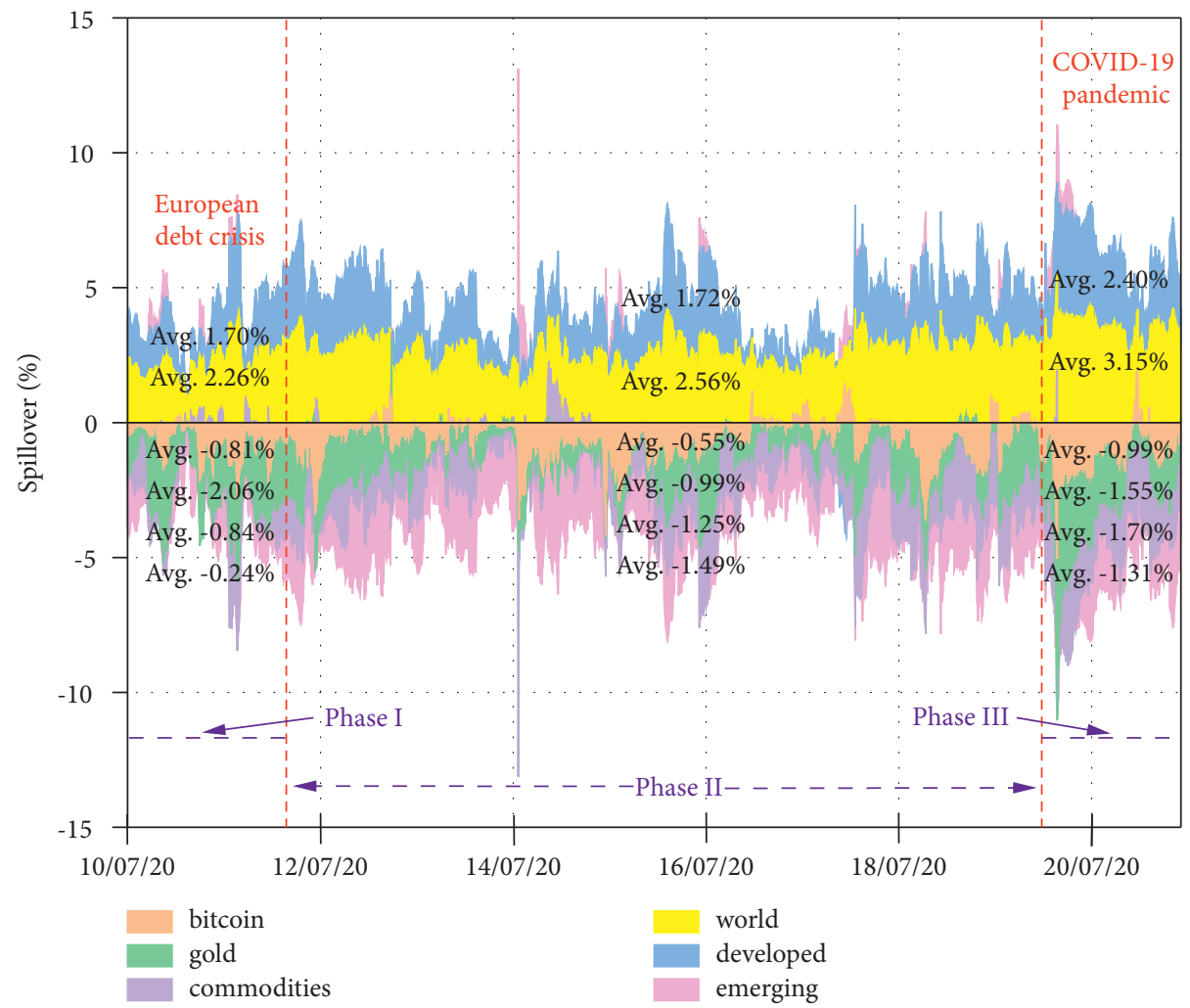

Figure 2: Dynamic return net total directional spillover for TVP-VAR. The different color areas define the accumulation of net total directional spillover. The net spillover of returns plotted here is computed by equation (12), which is defined as the difference in total directional connectedness to others and from others. All abbreviations are as follows: bitcoin, gold, and commodities indices (commodities); the world stock index (world); the developed stock index (developed); and the emerging stock index (emerging). The sample period for returns is from July 20, 2020, to June 23, 2021.

events on the sample markets. This result may be explained by that global investors prefer the commodity markets with the financialization of commodity assets for asset allocations.

In summary, the bitcoin, gold, and commodities indices have weak hedging effects on stock markets, and their abilities to act as safe-haven properties could be ranked as: commodities $>$ gold $>$ bitcoin.

4.3. Directional Spillover. Figures 3 and 4 show the return dynamic total directional "to" and "from" spillover, respectively (defined in equations (10) and (11)). The following conclusions are obtained.

Firstly, the spillover effects change over time. To be more specific, the spillover effects of the stock market declined when the European debt crisis ended and is less fluctuated when the economy is stable, but the spillover effects of the system increased rapidly during the outbreak of COVID-19. In other words, the spillover in phase II is smaller than in phases I and III in all markets.

Secondly, "to" and "from" represent the opposite relationship. The directional spillover almost changes after the outbreak of the extreme events. The net directional spillover is figured by the difference between the "to" and "from" (defined in equation (12)). In Figures 3 and 4, there is a clear trend that the spillover of "from" is invariably greater than "to" for bitcoin, gold, and commodities markets in all phases. This result further supports that the idea that bitcoin, gold, and commodities have weak hedging effects on stock markets, and it is in line with the results in the section above.

Thirdly, the row "to" (defined in equation (10)) indicates the total spillover effects transmitted by market $j$ to all other markets. From Figure 3, since that the "to" spillovers of bitcoin, gold, and commodities markets are less than the "from" spillovers, these three markets are defined as the net spillover recipients. Furthermore, a downward trend of the total directional spillover of commodities from other markets is witnessed after the European debt crisis, ranging from $8.54 \%$ to $3.91 \%$. However, when the COVID-19 erupted in January 2020, the spillover increased rapidly from $3.91 \%$ to $5.12 \%$. The European debt crisis and COVID-19 pandemic eruption significantly increased the total directional spillover from other markets to commodities. Another similar example is gold, after March 2012 and COVID-19 pandemic; the directional spillover from other markets to gold declined rapidly from $4.17 \%$ to $2.27 \%$, then to $3.07 \%$. Bitcoin also has a similar tendency; particularly, the total directional spillover from other markets to bitcoin increases at a rapid rate from $0.99 \%$ to $4.60 \%$ when the COVID- 19 pandemic occurs.

Finally, the column "from" (defined in equation (11)) indicates the total spillovers received by market $j$ from all other markets. As is shown in Figure 4, world and developed stock 


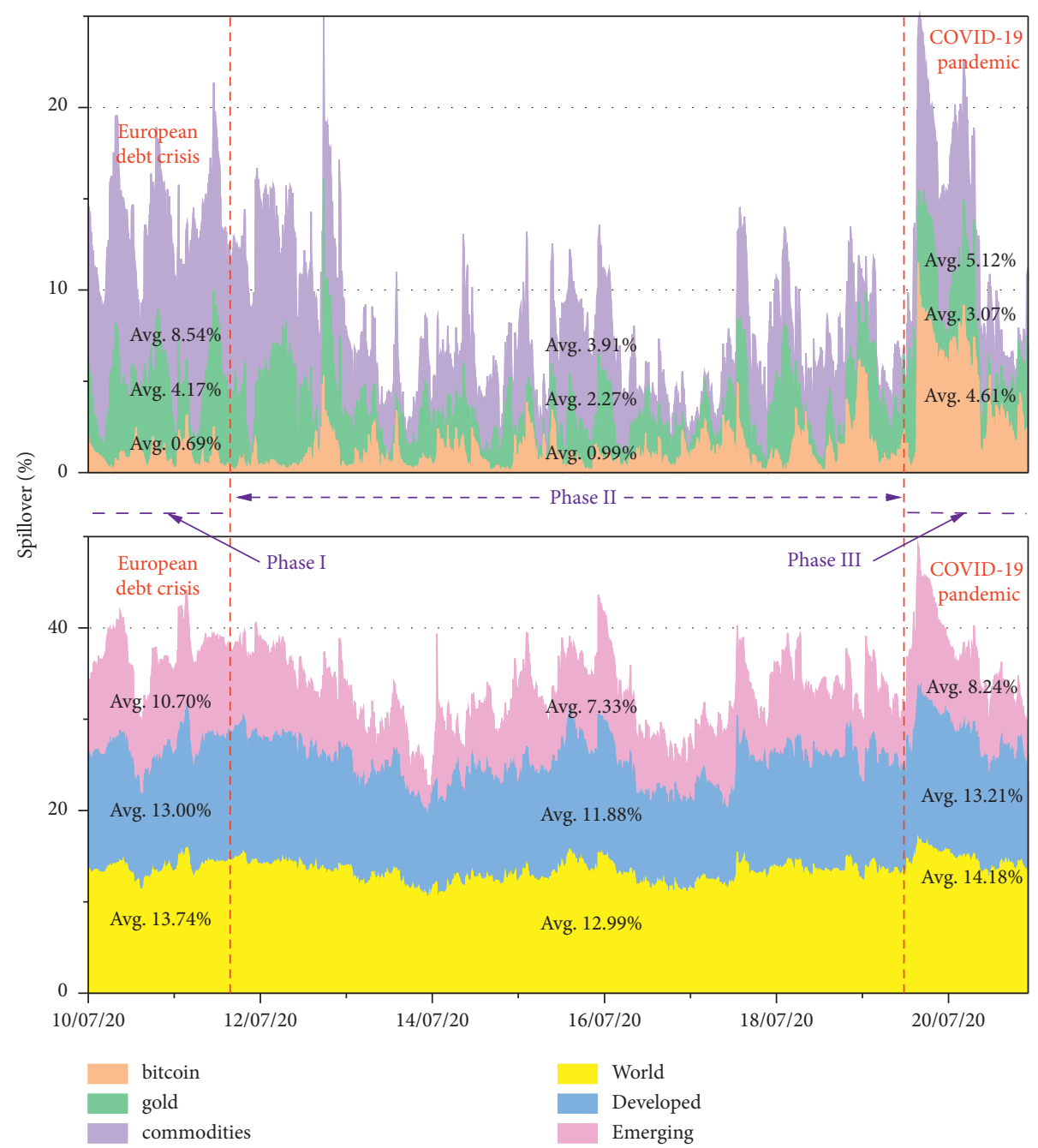

Figure 3: Dynamic total directional spillover to others for TVP-VAR. The different color areas define the accumulation of total directional spillover to other markets. The total directional spillover to others of returns plotted here is computed by equation (10), which is defined as the difference in total directional connectedness to others. All abbreviations are as follows: bitcoin, gold, and commodities indices (commodities); the world stock index (world); the developed stock index (developed); and the emerging stock index (emerging). The sample period for returns is from July 20, 2020, to June 23, 2021.

markets act as the net spillover transmitters in the sample for that these markets" "to" spillovers are not lower than "from" spillovers. In addition, the tendency of directional spillover effects of other markets from the world and developed markets are similar. The value of the directional spillover from developed stock markets to other markets declines from $11.30 \%$ to $10.16 \%$ after the European debt crisis in phase II to $10.81 \%$ in January 2020 . However, the directional spillover of other markets from the emerging stock market (10.94\%, 8.82\%, and $9.55 \%$, respectively) are greater than "to" (10.70\%, $7.33 \%$, and $8.24 \%$ successively) in each stage. Hence, the most striking observation from the data is that the emerging stock market acts as the net spillover recipient. A possible explanation for this may be the absence of adequate information technology and core competitiveness for the emerging stock market to develop.

\section{Robustness Test}

In this section, we further conduct robustness checks of our major empirical results made in Section 4 by using a mixed methodology model based on Diebold and Yilmaz [28]. What is more, it is made up of a static spillover measurement (on time domain) and a dynamic framework on three rolling windows (i.e., 80, 100, and 120 lengths).

5.1. Static Spillover on the Time Domain. From the perspective of the static spillover measurement [28], we mainly study the correlation among bitcoin, gold, commodities, and three stock markets. Table 2 displays the static spillover measures between each market on the time domain during the entire phase and three sample phases. 


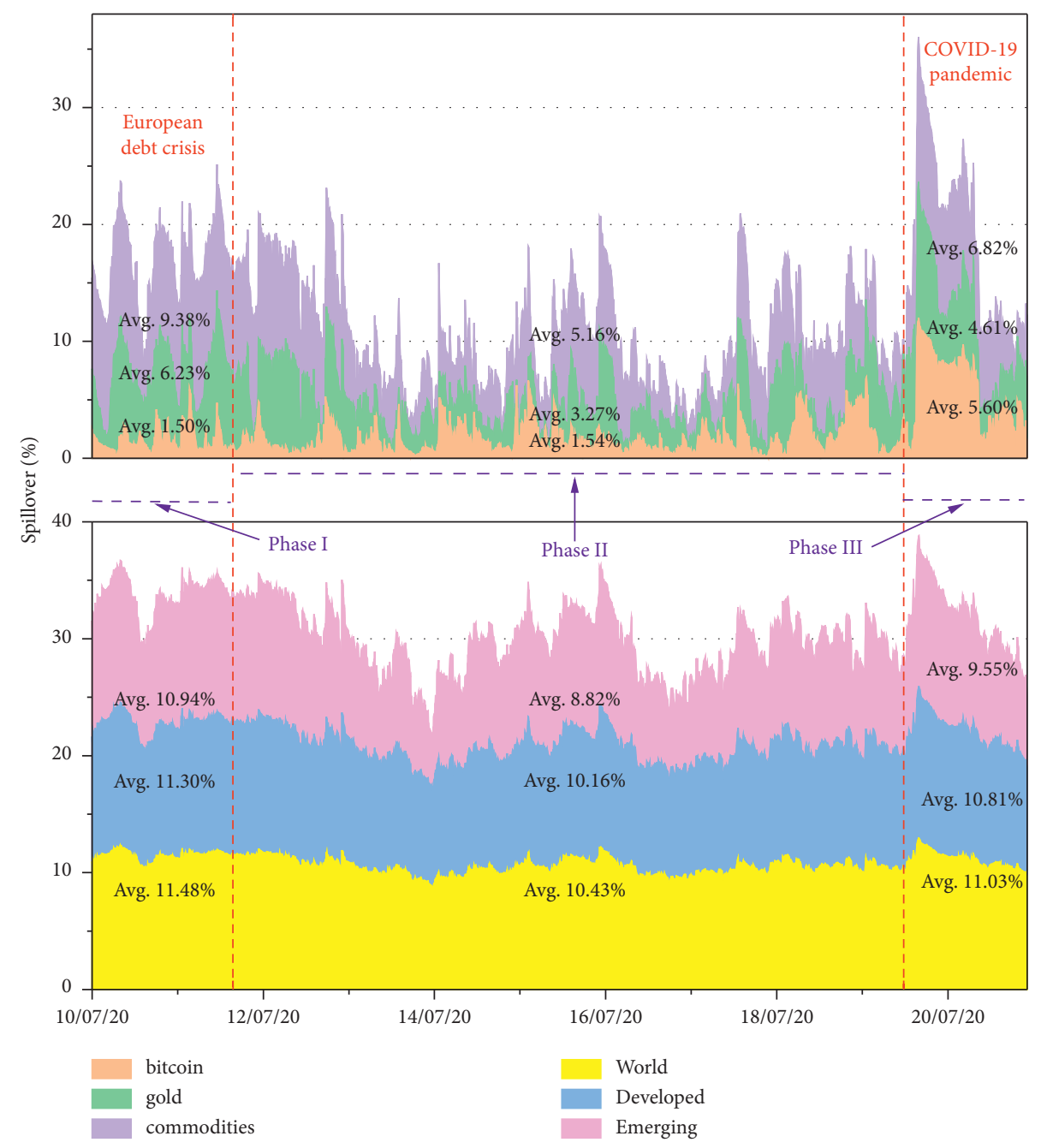

Figure 4: Total directional spillover from others for TVP-VAR. The different color areas define the accumulation of total directional spillover from other markets. The total directional spillover from others of returns plotted here is computed by equation (11), which is defined as the difference in total directional connectedness from others. All abbreviations are as follows: bitcoin, gold, and commodities indices (commodities); the world stock index (world); the developed stock index (developed); and the emerging stock index (emerging). The sample period for returns is from July 20, 2020, to June 23, 2021.

First of all, it is noticeable that the total connectedness in phase II is $35.11 \%$, while in phase I and phase III it is $47.15 \%$ and $49.96 \%$, respectively, which are higher than the total connectedness in phase II, demonstrating a relatively strong information spillover after the European debt crisis and COVID-19 outbreak. This result is in accordance with Section 4.1.

Secondly, from the net values of the entire phase in Table 2, we can see that the spillovers of bitcoin, gold, commodities, and emerging stock markets are negative, illustrating these markets play the role of net spillover recipients. Nevertheless, the world and developed stock markets are net spillover transmitters since the spillover effects are $2.32 \%$ and $1.66 \%$, respectively. Furthermore, the results of the net spillover recipient prove that bitcoin, gold, and commodities can be seen as safe-haven assets, and the ranking of their abilities is: commodities $(-1.86 \%)>$ gold $(-0.47 \%)>$ bitcoin $(-0.16 \%)$. These results are in consistent with those obtained by the former results.
What is more, there is a clear trend that the spillover of "from" is invariably greater than "to" for bitcoin, gold, commodities, and emerging markets while the spillovers of world and developed stock markets are opposite in all phases. Contrary to expectations, one unanticipated finding is the difference between the "to" and "from" of gold and commodities at phase I, where the value difference for gold $(-1.83 \%)$ is to be outbidding about commodities $(-0.81 \%)$.

5.2. Dynamic Test with Different Rolling Windows. In estimating the robustness of the above empirical results, we set the 3 dynamic rolling window sizes of 80,100 , and 120 equivalent to left 2,625, 2,605, and 2,585 out-of-sample observations, respectively. By the way of orientation, we also compute the total, net, "to," and "from" spillover spanning from the 3 rolling windows.

From Figure 5, we can see the six markets total spillover based on three different rolling window sizes (i.e., 80, 100, and 
TABLE 2: Full-sample return spillover measures in the static time domain.

\begin{tabular}{|c|c|c|c|c|c|c|c|}
\hline & Bitcoin & Gold & Commodities & World & Developed & Emerging & From \\
\hline \multicolumn{8}{|l|}{ Entire phase } \\
\hline Bitcoin & 98.14 & 0.30 & 0.16 & 0.63 & 0.71 & 0.06 & 0.31 \\
\hline Gold & 0.23 & 92.60 & 3.73 & 1.04 & 0.91 & 1.49 & 1.23 \\
\hline Commodities & 0.11 & 2.48 & 61.60 & 13.21 & 12.70 & 9.90 & 6.40 \\
\hline World & 0.23 & 0.41 & 7.78 & 35.74 & 35.45 & 20.39 & 10.71 \\
\hline Developed & 0.27 & 0.36 & 7.70 & 36.74 & 37.04 & 17.89 & 10.49 \\
\hline Emerging & 0.06 & 1.08 & 7.86 & 26.55 & 23.17 & 41.27 & 9.79 \\
\hline To & 0.15 & 0.77 & 4.54 & 13.03 & 12.16 & 8.29 & 38.94 \\
\hline Net & -0.16 & -0.47 & -1.86 & 2.32 & 1.66 & -1.50 & \\
\hline \multicolumn{8}{|c|}{ Phase I: July 20, 2010-March 13, 2012} \\
\hline Bitcoin & 96.98 & 0.78 & 0.48 & 0.67 & 0.86 & 0.22 & 0.50 \\
\hline Gold & 0.27 & 76.89 & 12.6 & 2.92 & 2.52 & 4.79 & 3.85 \\
\hline Commodities & 0.07 & 7.12 & 43.72 & 17.34 & 16.66 & 15.09 & 9.38 \\
\hline World & 0.18 & 1.07 & 12.81 & 32.16 & 31.96 & 21.82 & 11.31 \\
\hline Developed & 0.25 & 0.94 & 12.68 & 32.96 & 33.19 & 19.97 & 11.13 \\
\hline Emerging & 0.05 & 2.26 & 12.9 & 26.51 & 24.16 & 34.13 & 10.98 \\
\hline To & 0.14 & 2.03 & 8.58 & 13.40 & 12.69 & 10.32 & 47.15 \\
\hline Net & -0.37 & -1.83 & -0.80 & 2.10 & 1.56 & -0.66 & \\
\hline \multicolumn{8}{|c|}{ Phase II: March 14, 2012-January 13, 2020} \\
\hline Bitcoin & 99.62 & 0.26 & 0.01 & 0.03 & 0.04 & 0.03 & 0.06 \\
\hline Gold & 0.09 & 97.04 & 2.39 & 0.06 & 0.07 & 0.35 & 0.49 \\
\hline Commodities & 0.03 & 1.73 & 71.25 & 10.22 & 9.81 & 6.96 & 4.79 \\
\hline World & 0.09 & 0.03 & 5.49 & 37.88 & 37.55 & 18.95 & 10.35 \\
\hline Developed & 0.1 & 0.01 & 5.45 & 39.04 & 39.49 & 15.9 & 10.08 \\
\hline Emerging & 0.06 & 0.49 & 5.39 & 27.07 & 22.97 & 44.03 & 9.33 \\
\hline To & 0.06 & 0.42 & 3.12 & 12.74 & 11.74 & 7.03 & 35.11 \\
\hline Net & -0.00 & -0.07 & -1.67 & 2.39 & 1.65 & -2.30 & \\
\hline \multicolumn{8}{|c|}{ Phase III: January 14, 2020-June 23, 2021} \\
\hline Bitcoin & 64.36 & 4.92 & 3.22 & 10.92 & 11.04 & 5.53 & 5.94 \\
\hline Gold & 5.93 & 77.88 & 2.09 & 5.35 & 5.29 & 3.46 & 3.69 \\
\hline Commodities & 3.02 & 1.47 & 54.66 & 14.93 & 14.5 & 11.42 & 7.56 \\
\hline World & 6.09 & 2.16 & 8.44 & 32.03 & 31.83 & 19.46 & 11.33 \\
\hline Developed & 6.51 & 2.15 & 8.31 & 32.69 & 32.87 & 17.46 & 11.19 \\
\hline Emerging & 3.45 & 2.59 & 9.35 & 24.49 & 21.71 & 38.41 & 10.27 \\
\hline To & 4.16 & 2.22 & 5.24 & 14.73 & 14.06 & 9.56 & 49.96 \\
\hline Net & -1.77 & -1.47 & -2.32 & 3.40 & 2.87 & -0.71 & \\
\hline
\end{tabular}

Note. (1) The bold value in the bottom right corner is the total connectedness computed in the system. (2) Values in the last row at each phase denote the net spillover of six markets that are mainly compared with Section 4.1. (3) The values of "to" or "from" represent the spillover that an individual market contributes or receives totally in the whole sample system. (4) All abbreviations are as follows: bitcoin, gold, and commodities indices (commodities); the world stock index (world); the developed stock index (developed); and the emerging stock index (emerging). (5) The entire phase for returns is from July 20, 2020, to June 23, 2021.

120 lengths) and the dynamic total spillover based on TVPVAR, and the estimated total spillovers remain the similar tendency. Total spillovers fell after the European debt crisis and then rose sharply when the outbreak of the COVID-19 pandemic by the selection of rolling window sizes, implying that the dynamic total spillover among the six markets has significant time-varying characteristics, and the total spillover effects increase significantly after extreme events occur. Consequently, the dynamic total spillover with different rolling windows confirms the robustness of the above empirical analysis results of Section 4.1 and the static test in Section 5.1.

Figure 6 exhibits the net directional spillover measures based on three different rolling window sizes (i.e., 80, 100, and 120 lengths); the results illustrate that exactly similar time-varying characteristics. Table 3 is organized by the average value of net directional spillover on the basis of Figure 6 , illustrating that the dynamic net spillovers of bitcoin, gold, commodities, and emerging markets are not positive, while the world and developed stock markets are non-negative with the three different rolling windows in all phases. Tables 4 and 5 provide, respectively, the mean dynamic "from" and "to" spillovers with different rolling windows in line with Figures 7 and 8 . These results show that developed and world stock markets act as the net spillover transmitters, while the emerging stock market and three possible safe-haven markets are the net recipients in all phases, similar to the results in Section 4.2. What calls for special attention is that the ranking of performance as a safehaven property seems to be inconsistent with former results. This difference can be explained by the loss of valid sample dates by rolling window lengths; thus, the net spillover effects of safe-haven assets are seriously affected. In summary, by setting different rolling window sizes, we further confirm the robustness of the conclusions obtained in Section 4.3. 


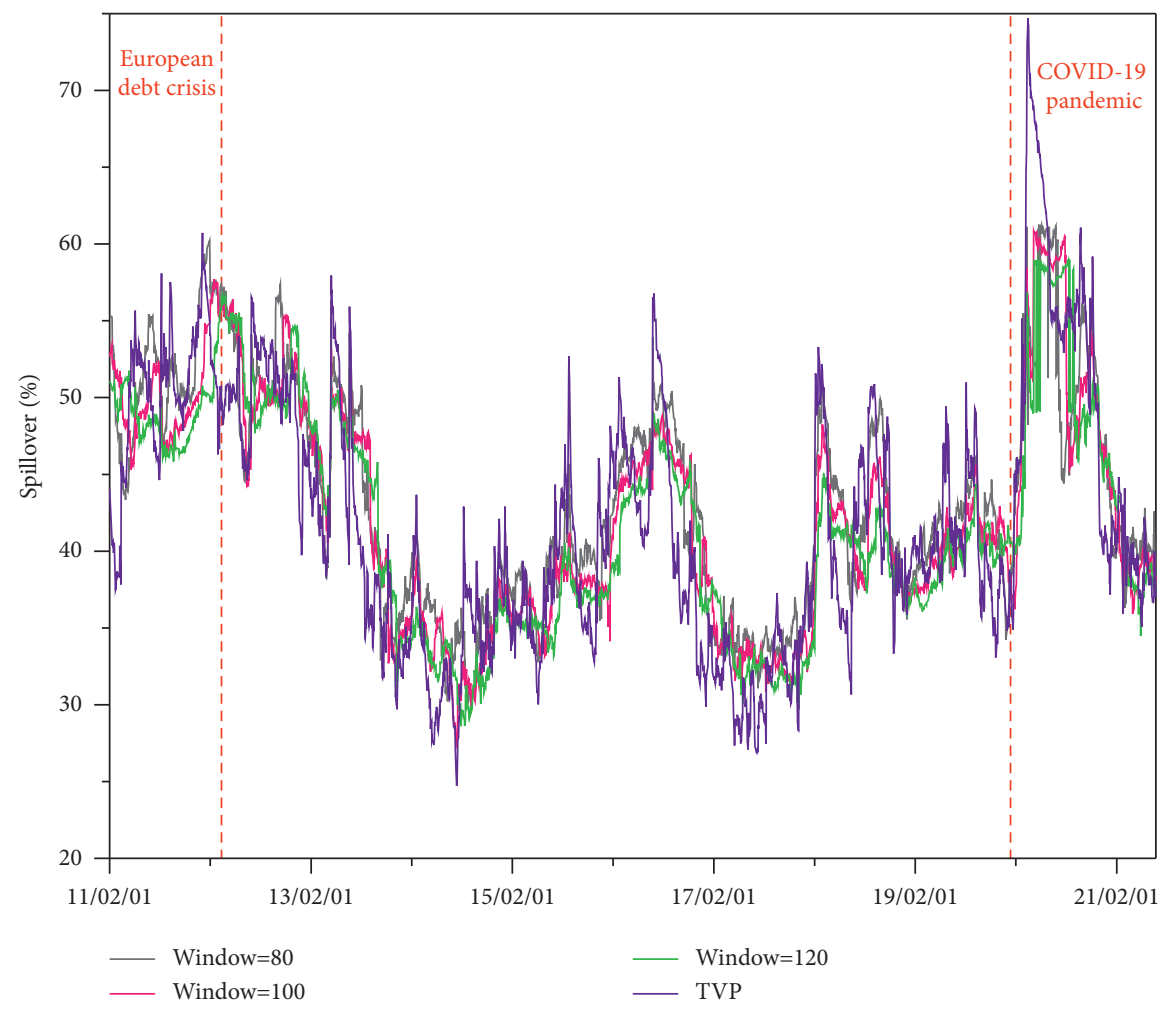

FIGURE 5: Dynamic return total spillover with different rolling windows and TVP-VAR. The blue line is the dynamic return total spillover for TVP-VAR. The red dotted line defines the time points that distinguish three sample phases. The three window sizes plot the dynamic return total spillover measures on the 80,100 , and 120. All abbreviations are as follows: bitcoin, gold, and commodities indices (commodities); the world stock index (world); the developed stock index (developed); and the emerging stock index (emerging). The sample period for returns is from February 2, 2011, to June 23, 2021.
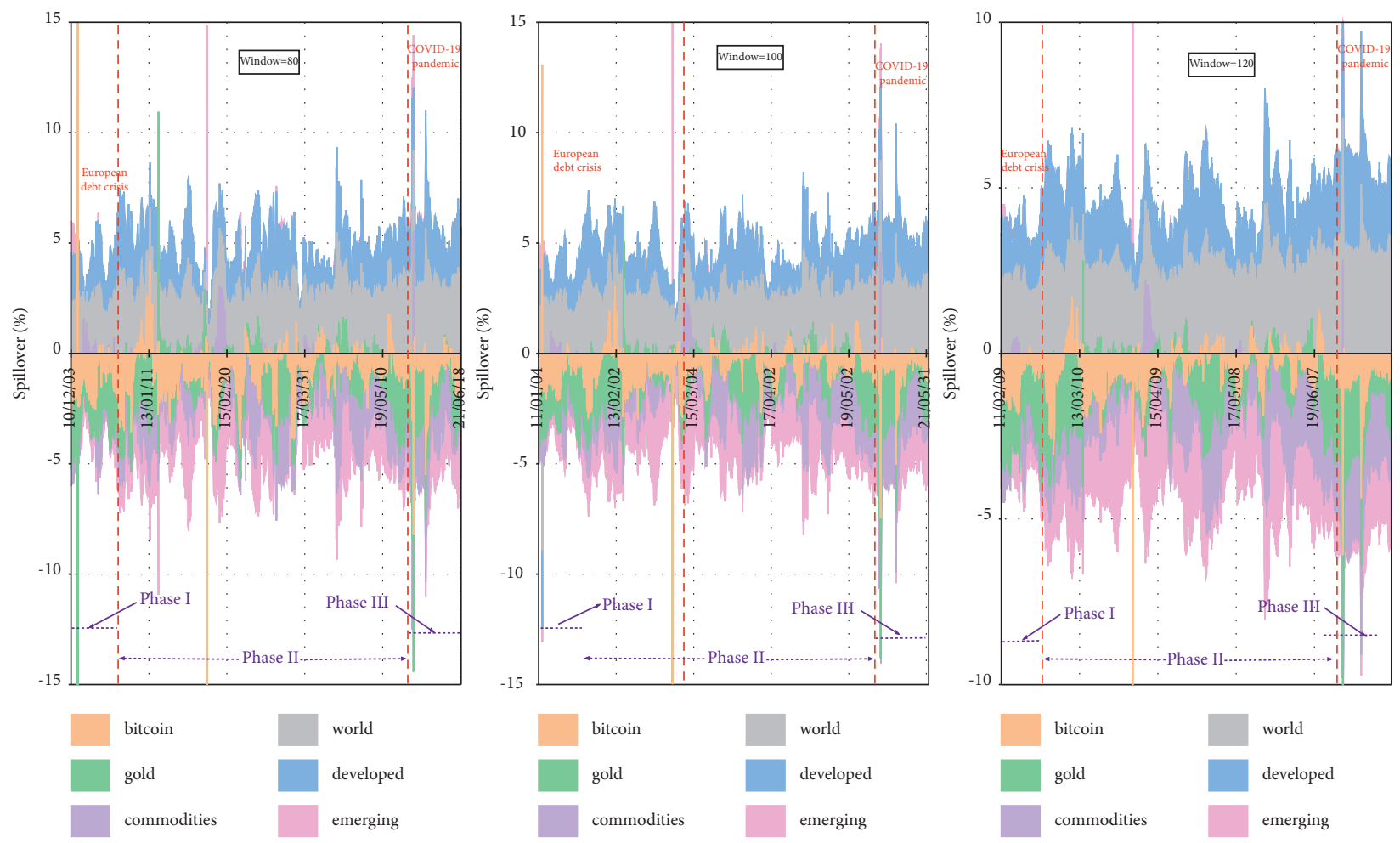

FIGURE 6: Dynamic net spillover with different rolling windows. The red dotted line defines the time points that distinguish three sample phases. The three window sizes plot the dynamic return total spillover measures on the 80 (the sample period for returns is from December 8 , 2010 , to June 23, 2021), 100 (the sample period for returns is from January 4, 2011, to June 23, 2021), and 120 (the sample period for returns is from February 9, 2011, to June 23, 2021.). All abbreviations are as follows: bitcoin, gold, and commodities indices (commodities); the world stock index (world); the developed stock index (developed); and the emerging stock index (emerging). 
TABLE 3: Dynamic net spillover with different rolling windows.

\begin{tabular}{|c|c|c|c|}
\hline & Window $=80$ & Window $=100$ & Window $=120$ \\
\hline Phase I: & December 2, 2010-March 13, 2012 & December 31, 2010-March 13, 2012 & February 1, 2011-March 13, 2012 \\
\hline Bitcoin & -1.100 & -0.926 & -0.832 \\
\hline Gold & -1.829 & -1.759 & -1.700 \\
\hline Commodities & -0.549 & -0.596 & -0.620 \\
\hline World & 2.134 & 2.122 & 2.105 \\
\hline Developed & 1.629 & 1.582 & 1.550 \\
\hline Emerging & -0.283 & -0.421 & -0.501 \\
\hline \multicolumn{4}{|c|}{ Phase II: March 14, 2012-January 13, 2020} \\
\hline Bitcoin & -0.734 & -0.547 & -0.444 \\
\hline Gold & -0.841 & -0.799 & -0.773 \\
\hline Commodities & -1.301 & -1.289 & -1.274 \\
\hline World & 2.646 & 2.599 & 2.573 \\
\hline Developed & 1.919 & 1.865 & 1.838 \\
\hline Emerging & -1.689 & -1.828 & -1.919 \\
\hline \multicolumn{4}{|c|}{ Phase III: January 14, 2020-June 23, 2021} \\
\hline Bitcoin & -0.937 & -0.818 & -0.829 \\
\hline Gold & -1.755 & -1.741 & -1.665 \\
\hline Commodities & -1.848 & -1.989 & -2.078 \\
\hline World & 3.283 & 3.264 & 3.252 \\
\hline Developed & 2.485 & 2.503 & 2.529 \\
\hline Emerging & -1.229 & -1.219 & -1.209 \\
\hline
\end{tabular}

Note. The values are produced by the average value of net directional spillover on the basis of Figure 6. All abbreviations are as follows: bitcoin, gold, and commodities indices (commodities); the world stock index (world); the developed stock index (developed); and the emerging stock index (emerging). The sample period for returns is from July 20, 2020, to June 23, 2021.

TABLE 4: Dynamic from spillover with different rolling windows.

\begin{tabular}{|c|c|c|c|}
\hline & Window $=80$ & Window $=100$ & Window $=120$ \\
\hline Phase I: & December 2, 2010-March 13, 2012 & December 31, 2010-March 13, 2012 & February 1, 2011-March 13, 2012 \\
\hline Bitcoin & 2.028 & 1.747 & 1.451 \\
\hline Gold & 6.330 & 5.519 & 4.741 \\
\hline Commodities & 9.444 & 9.522 & 9.349 \\
\hline World & 11.485 & 11.423 & 11.331 \\
\hline Developed & 11.318 & 11.247 & 11.149 \\
\hline Emerging & 10.998 & 11.015 & 10.917 \\
\hline \multicolumn{4}{|c|}{ Phase II: March 14, 2012-January 13, 2020} \\
\hline Bitcoin & 2.148 & 1.683 & 1.423 \\
\hline Gold & 3.045 & 3.196 & 3.005 \\
\hline Commodities & 4.929 & 5.283 & 5.199 \\
\hline World & 10.470 & 10.546 & 10.520 \\
\hline Developed & 10.209 & 10.293 & 10.264 \\
\hline Emerging & 9.265 & 9.421 & 9.404 \\
\hline \multicolumn{4}{|c|}{ Phase III: January 14, 2020-June 23, 2021} \\
\hline Bitcoin & 5.618 & 5.497 & 5.469 \\
\hline Gold & 5.141 & 4.763 & 4.518 \\
\hline Commodities & 6.767 & 6.672 & 6.652 \\
\hline World & 11.063 & 11.048 & 11.063 \\
\hline Developed & 10.833 & 10.828 & 10.853 \\
\hline Emerging & 9.598 & 9.629 & 9.690 \\
\hline
\end{tabular}

Note. The values are produced by the average value of total directional spillover from others on the basis of Figure 7. All abbreviations are as follows: bitcoin, gold, and commodities indices (commodities); the world stock index (world); the developed stock index (developed); and the emerging stock index (emerging).

TABLE 5: Dynamic to spillover with different rolling windows.

\begin{tabular}{lccc}
\hline & Window $=80$ & Window $=100$ & Window $=120$ \\
\hline Phase I: & December 2, 2010-March 13, 2012 & December 31, 2010-March 13, 2012 & February 1, 2011-March 13, 2012 \\
Bitcoin & 1.131 & 0.821 & 0.619 \\
Gold & 4.496 & 3.759 & 3.041 \\
\hline
\end{tabular}


TABLE 5: Continued.

\begin{tabular}{|c|c|c|c|}
\hline & Window $=80$ & Window $=100$ & Window $=120$ \\
\hline Commodities & 9.126 & 8.925 & 8.729 \\
\hline World & 13.665 & 13.546 & 13.436 \\
\hline Developed & 12.993 & 12.829 & 12.699 \\
\hline Emerging & 10.856 & 10.594 & 10.414 \\
\hline \multicolumn{4}{|c|}{ Phase II: March 14, 2012-January 13, 2020} \\
\hline Bitcoin & 1.368 & 1.135 & 0.979 \\
\hline Gold & 2.617 & 2.397 & 2.232 \\
\hline Commodities & 4.159 & 3.993 & 3.925 \\
\hline World & 13.236 & 13.146 & 13.093 \\
\hline Developed & 12.259 & 12.158 & 12.102 \\
\hline Emerging & 7.772 & 7.593 & 7.485 \\
\hline \multicolumn{4}{|c|}{ Phase III: January 14, 2020-June 23, 2021} \\
\hline Bitcoin & 4.681 & 4.678 & 4.639 \\
\hline Gold & 3.386 & 3.022 & 2.853 \\
\hline Commodities & 4.919 & 4.683 & 4.574 \\
\hline World & 14.347 & 14.312 & 14.315 \\
\hline Developed & 13.318 & 13.330 & 13.382 \\
\hline Emerging & 8.369 & 8.409 & 8.481 \\
\hline
\end{tabular}

Note. The values are produced by the average value of total directional spillover to others on the basis of Figure 8. All abbreviations are as follows: bitcoin, gold, and commodities indices (commodities); the world stock index (world); the developed stock index (developed); and the emerging stock index (emerging).
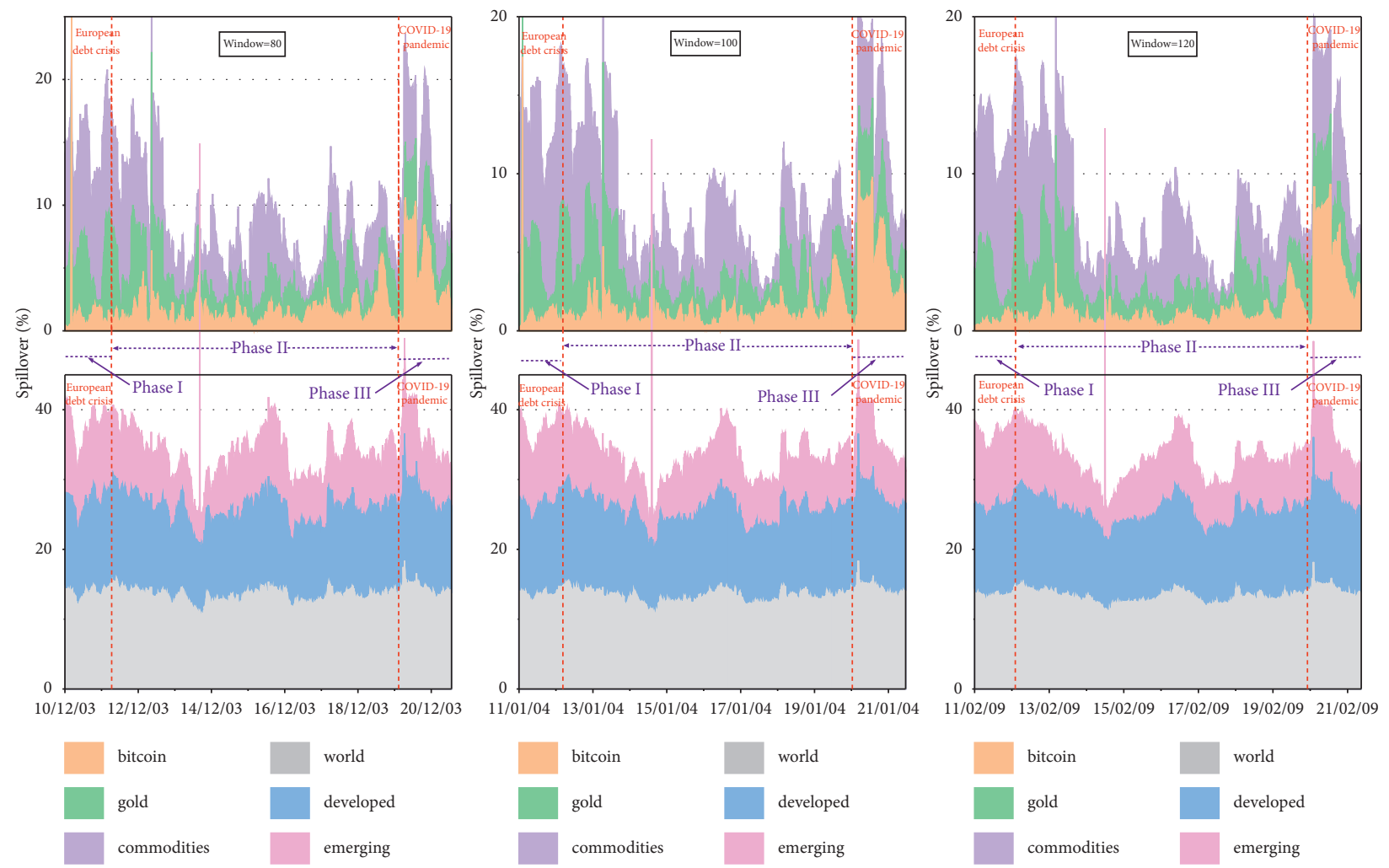

Figure 7: Dynamic net spillover to others with different rolling windows. The red dotted line defines the time points that distinguish three sample phases. The three window sizes plot the dynamic return total spillover measures on the 80 (the sample period for returns is from December 8, 2010, to June 23, 2021), 100 (the sample period for returns is from January 4, 2011, to June 23, 2021), and 120 (the sample period for returns is from February 9, 2011, to June 23, 2021). All abbreviations are as follows: bitcoin, gold, and commodities indices (commodities); the world stock index (world); the developed stock index (developed); and the emerging stock index (emerging). 

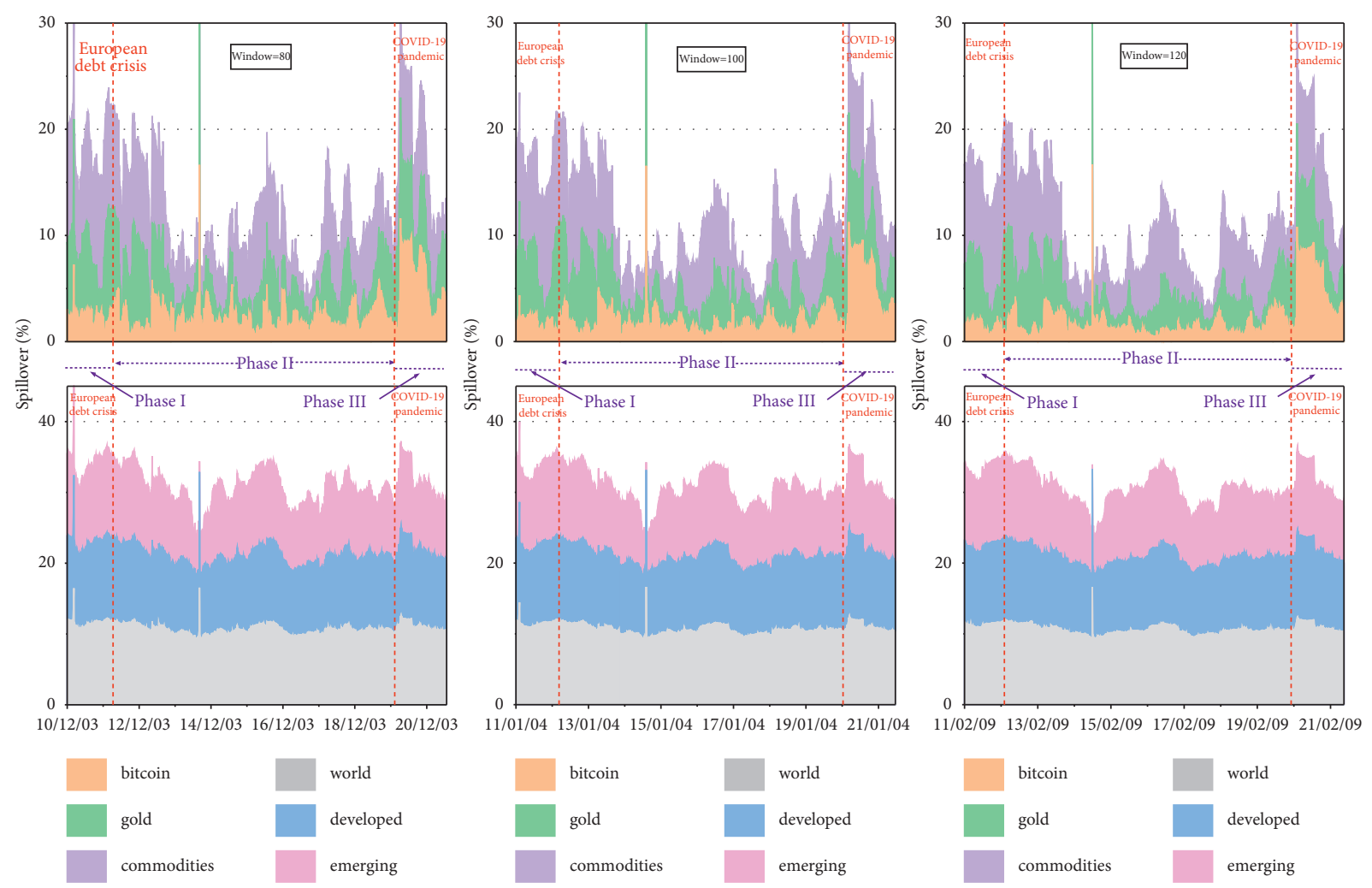

Figure 8: Dynamic net spillover from others with different rolling windows. The red dotted line defines the time points that distinguish three sample phases. The three window sizes plot the dynamic return total spillover measures on the 80 (the sample period for returns is from December 8, 2010, to June 23, 2021), 100 (the sample period for returns is from January 4, 2011, to June 23, 2021), and 120 (the sample period for returns is from February 9, 2011, to June 23, 2021). All abbreviations are as follows: bitcoin, gold, and commodities indices (commodities); the world stock index (world); the developed stock index (developed); and the emerging stock index (emerging).

\section{Conclusion}

The outbreak of extreme events has brought strong shocks to a range of stock markets. The purpose of the research is to examine whether bitcoin, gold, or commodities can provide investors with effective hedging instruments for international stock markets during the European debt crisis and COVID-19 pandemic.

Firstly, both the dynamic net directional spillover analysis and robustness test demonstrate that bitcoin, gold, and commodities all have weak hedging effects on stock markets, and their abilities to act as a safe-haven property are ranked as: commodities > gold > bitcoin. Specifically, in the dynamic net directional spillover analysis, the commodities market is identified to have the largest safe-haven property with the values of $-0.84 \%,-1.25 \%$, and $-1.70 \%$ in turn during the three periods, respectively. In addition, the bitcoin market is the smallest net spillover receiver with values of $-0.81 \%,-0.55 \%$, and $-0.99 \%$ in phases I, II, and III order, respectively. In the static time domain of the robustness test, the spillover effects of bitcoin, gold, and commodities are $-0.16 \%,-0.47 \%$, and $-1.86 \%$, respectively. What is more, the robustness check results further validate the empirical findings. Secondly, the dynamic return net directional spillover analysis directly shows that world (2.65\%) and developed (1.94\%) stock markets act as the net spillover transmitters, while bitcoin, gold, and commodities are the net recipients with a smaller "to" than "from" spillover. Thirdly, the dynamic total average spillovers increase significantly after extreme risk event occurs; to be more specific, the spillover effects of the market declined from $50.84 \%$ to $39.37 \%$ when the European debt crisis ended, but the spillover effects of the system increased rapidly to $48.43 \%$ when the outbreak of COVID-19, which means the contagion of risk is more sensitive when crises occur. Finally, the dynamic total spillover measurements reveal that the six markets' total spillover shows significant time-varying characteristics, ranging from almost $20 \%$ to $80 \%$, demonstrating the relatively strong information spillover among the bitcoin, gold, commodities, and three stock markets.

Given the fact of strong time-varying connectedness among bitcoin, gold, commodities, and stock markets, policymakers and international investors need to pay close attention to the spillover effects among them from time to time when making regulatory and investment decisions. In addition, the significant effects of the European debt crisis and COVID-19 pandemic on the dynamic spillover among the safe-haven assets and three major stock markets imply that policymakers and global investors should keep an eye on the factor of "black swan," which can alter assets' spillover relationship. Moreover, since the dynamic return net directional spillover analysis is quite significant, various 
economic supervision agents and international traders have to adjust their expectations and spillovers transmitted from other markets when making important decisions. They have to alter their expectations in time to avoid the negative impacts of shocks when the market policy changes. Last but not least, investors cannot ignore the importance of bitcoin, gold, and commodities in selecting preferable safe-haven assets when searching for more profitable portfolio policies and management strategies.

\section{Data Availability}

The bitcoin price was collected from https://coinmarketcap. com/. The gold price, commodity index, and three stock indices were subscribed from the Wind database.

\section{Conflicts of Interest}

The authors declare that there are no conflicts of interest in this paper.

\section{Authors' Contributions}

Qian Wang provided the original idea and wrote the draft of this paper. Yu Wei supervised the writing process of this paper. Yao Wang made the data collection. Yuntong Liu made the estimations of empirical models. All authors have read and agreed to the published version of the manuscript.

\section{Acknowledgments}

This research was funded by the National Natural Science Foundation of China (71671145 and 71971191), Science and Technology Innovation Team of Yunnan Provincial Universities (2019014), and Yunnan Fundamental Research Projects (202001AS070018).

\section{References}

[1] B. Keddad and C. Schalck, "Evaluating sovereign risk spillovers on domestic banks during the European debt crisis," Economic Modelling, vol. 88, pp. 356-375, 2020.

[2] V. G. Papavassiliou and H. Kinateder, "Information shares and market quality before and during the European sovereign debt crisis," Journal of International Financial Markets, Institutions and Money, vol. 72, 2021.

[3] L. Bai, Y. Wei, G. Wei, X. Li, and S. Zhang, "Infectious disease pandemic and permanent volatility of international stock markets: a long-term perspective," Finance Research Letters, vol. 40, Article ID 101709, 2021.

[4] E. Bouri, S. J. H. Shahzad, D. Roubaud, L. Kristoufek, and B. Lucey, "Bitcoin, gold, and commodities as safe havens for stocks: new insight through wavelet analysis," The Quarterly Review of Economics and Finance, vol. 77, pp. 156-164, 2020.

[5] X. Li and Y. Wei, "The dependence and risk spillover between crude oil market and China stock market: new evidence from a variational mode decomposition-based copula method," Energy Economics, vol. 74, pp. 565-581, 2018.

[6] S. J. H. Shahzad, E. Bouri, D. Roubaud, L. Kristoufek, and B. Lucey, "Is Bitcoin a better safe-haven investment than gold and commodities?" International Review of Financial Analysis, vol. 63, pp. 322-330, 2019.
[7] Y. Wei, S. Qin, X. Li, S. Zhu, and G. Wei, "Oil price fluctuation, stock market and macroeconomic fundamentals: evidence from China before and after the financial crisis," Finance Research Letters, vol. 30, pp. 23-29, 2019.

[8] M. Akhtaruzzaman, S. Boubaker, B. M. Lucey, and A. Sensoy, "Is gold a hedge or a safe-haven asset in the COVID-19 crisis?" Economic Modelling, vol. 102, 2021.

[9] H. Boubaker, J. Cunado, L. A. Gil-Alana, and R. Gupta, "Global crises and gold as a safe haven: evidence from over seven and a half centuries of data," Physica A: Statistical Mechanics and Its Applications, vol. 540, 2020.

[10] J. Jin, J. Yu, Y. Hu, and Y. Shang, "Which one is more informative in determining price movements of hedging assets? Evidence from Bitcoin, gold and crude oil markets," Physica A: Statistical Mechanics and Its Applications, vol. 527, 2019.

[11] Y. Wei, C. Liang, Y. Li, X. Zhang, and G. Wei, "Can CBOE gold and silver implied volatility help to forecast gold futures volatility in China? Evidence based on HAR and Ridge regression models," Finance Research Letters, vol. 35, 2020.

[12] M. B. Triki and A. Ben Maatoug, "The GOLD market as a safe haven against the stock market uncertainty: evidence from geopolitical risk," Resources Policy, vol. 70, 2021.

[13] Z. He, F. O'Connor, and J. Thijssen, "Is gold a sometime safe haven or an always hedge for equity investors? A markovswitching CAPM approach for US and UK stock indices," International Review of Financial Analysis, vol. 60, pp. 30-37, 2018.

[14] Q. Ji, D. Zhang, and Y. Zhao, "Searching for safe-haven assets during the COVID-19 pandemic," International Review of Financial Analysis, vol. 71, 2020.

[15] K.-M. Wang and Y.-M. Lee, "Is gold a safe haven for exchange rate risks? An empirical study of major currency countries," Journal of Multinational Financial Management, Article ID 100705, 2021.

[16] M. Disli, R. Nagayev, K. Salim, S. K. Rizkiah, and A. F. Aysan, "In search of safe haven assets during COVID-19 pandemic: an empirical analysis of different investor types," Research in International Business and Finance, vol. 58, 2021.

[17] C. Dwita Mariana, I. A. Ekaputra, and Z. A. Husodo, "Are Bitcoin and Ethereum safe-havens for stocks during the COVID-19 pandemic?" Finance Research Letters, vol. 38, Article ID 101798, 2021.

[18] A. Stensås, M. F. Nygaard, K. Kyaw, S. Treepongkaruna, and Z. Yang, "Can Bitcoin be a diversifier, hedge or safe haven tool?" Cogent Economics \& Finance, vol. 7, 2019.

[19] A. Kliber, P. Marszałek, I. Musiałkowska, and K. Świerczyńska, "Bitcoin: safe haven, hedge or diversifier? Perception of bitcoin in the context of a country's economic situation-a stochastic volatility approach," Physica A: Statistical Mechanics and Its Applications, vol. 524, pp. 246-257, 2019.

[20] E. Bouri, P. Molnár, G. Azzi, D. Roubaud, and L. I. Hagfors, "On the hedge and safe haven properties of Bitcoin: is it really more than a diversifier?" Finance Research Letters, vol. 20, pp. 192-198, 2017.

[21] T. Conlon and R. McGee, "Safe haven or risky hazard? Bitcoin during the Covid-19 bear market," Finance Research Letters, vol. 35, Article ID 101607, 2020.

[22] L. A. Smales, "Bitcoin as a safe haven: is it even worth considering?” Finance Research Letters, vol. 30, pp. 385-393, 2019.

[23] S. Choi and J. Shin, "Bitcoin: an inflation hedge but not a safe haven," Finance Research Letters, Article ID 102379, 2021. 
[24] T. E. Sønsteng Henriksen, "Properties of long/short commodity indices in stock and bond portfolios," Journal of Alternative Investments, vol. 20, pp. 51-68, 2018.

[25] S. Bekiros, S. Boubaker, D. K. Nguyen, and G. S. Uddin, "Black swan events and safe havens: the role of gold in globally integrated emerging markets," Journal of International Money and Finance, vol. 73, pp. 317-334, 2017.

[26] S. Ali, E. Bouri, R. L. Czudaj, and S. J. H. Shahzad, "Revisiting the valuable roles of commodities for international stock markets," Resources Policy, vol. 66, 2020.

[27] S. J. Hussain Shahzad, E. Bouri, D. Roubaud, and L. Kristoufek, "Safe haven, hedge and diversification for G7 stock markets: gold versus bitcoin," Economic Modelling, vol. 87, pp. 212-224, 2020.

[28] F. X. Diebold and K. Yilmaz, "Better to give than to receive: predictive directional measurement of volatility spillovers," International Journal of Forecasting, vol. 28, no. 1, pp. 57-66, 2012.

[29] M. Del Negro and G. E. Primiceri, "Time varying structural vector autoregressions and monetary policy: a corrigendum," The Review of Economic Studies, vol. 82, no. 4, pp. 1342-1345, 2015.

[30] H. H. Pesaran and Y. Shin, "Generalized impulse response analysis in linear multivariate models," Economics Letters, vol. 58, no. 1, pp. 17-29, 1998.

[31] F. X. Diebold and K. Yilmaz, "Measuring financial asset return and volatility spillovers, with application to global equity markets," The Economic Journal, vol. 119, no. 534, pp. $158-171,2009$.

[32] F. X. Diebold and K. Yilmaz, "On the network topology of variance decompositions: measuring the connectedness of financial firms," Journal of Econometrics, vol. 182, pp. 119-134, 2011. 